Available Online at http://journal.umgo.ac.id/index.php/madu

\title{
Pelatihan Stimulasi Deteksi Intervensi Dini Tumbuh Kembang Terhadap Cara Ibu Melakukan Stimulasi Perkembangan Anak
}

\section{Stimulation Training, Detection, Early Intervention For Growth And Development Of The Way Mothers Stimulate Child Development}

\author{
Suriani B, Fitriati Sabur, Djuhadiah Saadong, Amelia Wong \\ Poltekkes Kemenkes Makassar Jurusan Kebidanan \\ (email :fitriati_sabur@poltekkes-mks.ac.id)
}

\begin{abstract}
Development of Stimulation, Detection and Early Development (SDIDTK) is a comprehensive activity carried out with families, communities and professionals to produce quality child development processes. This study aims to determine the effect of SDIDTK training on the way mothers stimulate child development in Karunrung Village, Makassar City. This type of research is quasi-experimental with the one group pretest-posttest approach. The population of this study were all mothers who had children aged 3-60 months with a sampling technique using proportional stratified random sampling of 30 mothers with sufficient sample using the lamesow formula. The instruments used were the KPSP questionnaire and the observation sheet adopted from the Ministry of Health of the Republic of Indonesia in 2010 and data analysis used T Test. The results showed that the mother's way of stimulating child development before the training intervention with a mean value of 61.00 and after the training intervention with a mean value of 87.66 where the value of $p=0.000$ and the value of $\alpha=0.05$, value of $p<v a l u e$ of $\alpha$ so that it can be concluded that SDIDTK training affects the way mothers stimulate child development with the strength of correlation which is good

Keywords: Stimulation, detection and early intervention of growth and development, a way to stimulate children's growth and development
\end{abstract}

\begin{abstract}
ABSTRAK
Pengembangan Stimulasi, Deteksi, dan Perkembangan Dini (SDIDTK) merupakan kegiatan komprehensif yang dilakukan bersama keluarga, masyarakat, dan tenaga profesional untuk menghasilkan proses tumbuh kembang anak yang berkualitas. Penelitian ini bertujuan untuk mengetahui pengaruh pelatihan SDIDTK terhadap cara ibu menstimulasi tumbuh kembang anak di Desa Karunrung Kota Makassar. Jenis penelitian ini adalah eksperimen semu dengan pendekatan one group pretest-posttest. Populasi dalam penelitian ini adalah seluruh ibu yang memiliki anak usia 3-60 bulan dengan teknik pengambilan sampel menggunakan proporsional stratified random sampling sebanyak 30 ibu dengan sampel cukup menggunakan rumus lamesow. Instrumen yang digunakan adalah angket KPSP dan lembar observasi yang diadopsi dari Kementerian Kesehatan Republik Indonesia tahun 2010 dan analisis datanya menggunakan Uji T. Hasil penelitian menunjukkan bahwa cara ibu menstimulasi tumbuh kembang anak sebelum dilakukan intervensi pelatihan dengan nilai mean 61.00 dan setelah intervensi pelatihan dengan nilai mean 87.66 dimana nilai $\mathrm{p}=0.000$ dan nilai $\alpha=0.05$, nilai $\mathrm{p}<$ nilai $\alpha$ sehingga dapat disimpulkan bahwa pelatihan SDIDTK berpengaruh terhadap cara ibu menstimulasi tumbuh kembang anak dengan kekuatan korelasi yang baik

Kata Kunci: Stimulasi, deteksi dan intervensi dini tumbuh kembang, cara stimulasi tumbuh kembang anak
\end{abstract}


Available Online at http://journal.umgo.ac.id/index.php/madu

\section{PENDAHULUAN}

Lima tahun pertama kehidupan anak merupakan masa keemasan atau golden period sekaligus masa kritis karena pada masa inilah terbentuk dasar-dasar kemampuan keindraan, berfikir, berbicara serta pertumbuhan mental intelektual yang intensif dan awal partum buhan moral. Kecepatan proses pertumbuhan dan perkembangan setiap anak berbeda - beda yang dipengaruhi oleh beberapa faktor diantaranya adalah faktor genetik, lingkungan sejak masa prenatal, perinatal dan post natal serta faktor pendidikan ibu, penghasilan keluarga, jumlah anak, beban kerja ibu, pola asuh, psikososial, kepribadian orang tua, adat istiadat, agama, urbanisasi, kehidupan berpo litik dan stimulasi yang diberikan oleh orang tua. ${ }^{1}$ Tahap perkembangan seorang anak mengikuti pola yang teratur dan berurutan. Tahap-tahap tersebut tidak bisa terjadi terbalik, misalnya anak mampu berjalan dahulu sebelum bisa berdiri. ${ }^{2}$ Faktor - faktor tersebut berperan dalam meningkatkan risiko terjadinya keterlambatan dalam proses pertumbuhan dan perkembangan anak balita (Bawah lima tahun). Keterlambatan perkembangan tersebut mayo ritas terjadi pada usia 4-5 tahun dimana jenis gangguan pertumbuhan dan perkem bangan terjadi pada tahap perkembangan motorik sebesar $27,5 \%$ atau sebanyak 3 juta orang anak yang mengalami gangguan pertumbuhan dan perkembangan. ${ }^{3}$ Jumlah anak usia dini (usia 06 tahun) sebanyak 26,09 juta, dari jumlah tersebut terdapat 12,6 juta anak yang berusia 45 tahun dan terdapat 384.800 orang $(3,05 \%)$ anak diantaranya mengalami keterlambatan perkembangan. ${ }^{4}$. Sekitar 5 hingga $10 \%$ anak diperkirakan mengalami keterlambatan perkembangan Sekitar 1-3\% anak di bawah usia 5 tahun mengalami keterlambatan perkemba ngan tersebut. ${ }^{5}$ Berdasarkan pengambilan data awal yang dilakukan oleh peneliti di Kelurahan Karunrung kota Makassar diperoleh data bahwa dari 472 orang balita dari $9 \mathrm{RW}$, terdapat 109 orang anak yang mengalami gangguan tumbuh kembang.

Gangguan perkembangan bicara dan bahasa merupakan gangguan perkembangan yang sering ditemukan pada anak usia 3-6 tahun dengan frekuensi kejadian berkisar antara $1 \%$ sampai $32 \%$ pada populasi yang normal. ${ }^{6}$

Terdapat 12 orang anak dengan perkem bangan abnormal, 15 orang anak dengan perkembangan meragukan dan terdapat 1 orang anak dengan perkembangan normal pada bayi usia 6-12 bulan di Kecamatan Rappocini Kota Makassar. ${ }^{7}$

Salah satu faktor pemicu terhambatnya tingkat keberhasilan stimulasi dini dan intervensi dini pada balita adalah tidak adanya dukungan dari orang lain khusus nya keluarga dan tenaga kesehatan. Mereka cenderung melakukannya sendiri dengan cara meniru orang tua terdahulu atau orang lain disekitar lingkungan yang sudah memiliki anak. ${ }^{8}$

Salah satu upaya untuk meningkatkan kemampuan ibu dalam memberikan asu han bersumber pada falsafah 'asah', 'asih', 'asuh'. Melalui program pembelajaran atau pelatihan terkait proses tumbuh kembang anak

Tujuan penelitian ini untuk mengetahui pengaruh pemberian pelatihan SDIDTK terhadap cara ibu dalam melakukan stimulasi perkembangan anak usia $3-60$ bulan di Kelurahan Karunrung Kota Makassar Tahun 2018. Terkait hal tersebut, peneliti tertarik melakukan penelitian tentang "Pengaruh Pemberian Pelatihan SDIDTK Terhadap Cara Ibu Melakukan Stimulasi perkembangan Anak di Kelurahan Karunrung Kota Makassar"

\section{BAHAN DAN METODE}

Jenis penelitian ini bersifat quasi ekspe rimen dengan pendekatan one group pretestposttest yang berlokasi di Kelurahan Karun rung Kota Makassar pada bulan Februari April 2018 dengan populasi semua ibu yang 


\section{Available Online at http://journal.umgo.ac.id/index.php/madu}

memiliki anak usia 3 - 60 bulan sebanyak 472 orang dengan teknik pengambilan sampel secara Proporsionate Stratified Random Sam pling sebanyak 30 orang dengan kecukupan sampel menggunakan rumus lamesow. Pengumpulan data secara primer dilakukan dengan cara wawancara dan observasi dalam bentuk ceklist serta data sekunder terkait nama - nama ibu yang memiliki anak usia $3-60$ bulan. Instrument dalam penelitian ini meng gunakan kuesioner KPSP dan lembar observasi yang diadopsi dari Kementerian Kesehatan RI tahun 2016. ${ }^{10}$ Teknik analisis data ada dua tahapan yaitu: analisis univariate untuk menggambarkan pola data penelitian yang ada serta analisis secara bivariate dengan meng gunakan rumus Uji $T$ Paired Sample Test dengan nilai $\mathrm{d}=5 \%(0,05)$. dengan bantuan software pengolahan data dan disajikan dalam bentuk tabel.

\section{HASIL}

Berdasarkan hasil penelitian dari 30 responden yang terbagi menjadi 2 karak teristik yaitu ibu yang memiliki anak usia 3 - 30 bulan sebanyak 9 orang dan ibu yang memiliki anak usia 31 - 60 bulan sebanyak 21 orang diperoleh data bahwa ibu yang memiliki anak usia 3 - 30 bulan menda patkan nilai pre test sebesar 4,6 $(0,046 \%)$ dan nilai post test sebesar 7,4 (0,074 $\%)$ sedangkan ibu yang memiliki anak usia 31 - 60 bulan mendapatkan nilai pre test sebesar $6,7(0,067 \%)$ dan nilai post test sebesar 9,3 $(0,093 \%)$ sebagaimana tertera dalam tabel di bawah ini.

\begin{tabular}{|c|c|c|c|c|c|c|}
\hline \multicolumn{7}{|c|}{$\begin{array}{l}\text { Tabel } 1 \text { Perbedaan Nilai Standar Deviasi dalam } \\
\text { melakukan stimulasi perkembangan } \\
\text { anak berdasarkan kelompok umur } \\
\text { anak }\end{array}$} \\
\hline \multirow{3}{*}{$\begin{array}{l}\text { Umur } \\
(\mathrm{B} \ln )\end{array}$} & \multicolumn{6}{|c|}{ Nilai } \\
\hline & \multicolumn{3}{|c|}{ Pre Test } & \multicolumn{3}{|c|}{ Post Test } \\
\hline & $\sum$ & $\%$ & $S$ & $\sum$ & $\%$ & $S$ \\
\hline . & 4,6 & 0,046 & 5 & 7,4 & 0,074 & 2,5 \\
\hline $31-60$ & 6,7 & 0,067 & 14 & 9,3 & 0,093 & 12 \\
\hline
\end{tabular}

Sumber : Data Primer, 2018

Berdasarkan Tabel 1 diatas, menunjukkan peningkatan nilai test setelah diberikan pelatihan SDIDTK pada ibu yang berarti bahwa pelatihan SDIDTK dapat mening katkan nilai / kemampuan ibu dalam melakukan stimulasi perkembangan anak usia 3 - 60 bulan di Kelurahan Karunrung Kota Makassar. 
Madu

Jurnal Kesehatan
Vol 9, No 2 (2020), 14-20

ISSN 2301-5683 (print)

DOI: 10.31314/mjk.9.2.14-20.2020

Available Online at http://journal.umgo.ac.id/index.php/madu

Tabel 2. Analisis pengaruh pemberian pelatihan SDIDTK terhadap cara ibu melakukan stimulasi perkembangan anak

\begin{tabular}{cccccc}
\hline Intervensi & Sampel & Mean & Standar . Deviasi & Standar Error Mean & P \\
\cline { 1 - 5 } Sebelum & 30 & 61,000 & 2.17113 & 39639 & \\
Setelah & 30 & 87,667 & 1.75545 & 32050 & 0,000 \\
\hline
\end{tabular}

Sumber : Data Primer, 2018

Hasil analisis berdasarkan Uji T Paired sample test pada tabel 2 di atas menunjukkan bahwa terdapat pengaruh pembe rian pelatihan SDIDTK terhadap cara ibu melakukan stimulasi perkembangan anak usia $3-60$ bulan dengan nilai $\mathrm{p}=0.000, \alpha=0.05(\mathrm{p}<\alpha)$ dengan kekuatan korelasi yang cukup. Peningkatan kemampuan ibu dalam melakukan SDIDTK tersebut dapat memudahkan ibu dalam melakukan identifikasi dini penyimpangan perkem bangan anaknya sehingga dapat segera ditangani dengan baik oleh tenaga kesehatan.

\section{PEMBAHASAN}

Terdapat $12,4 \%$ anak yang mengalami gangguan perkembangan motorik kasar dan sebesar 9,8 \% anak mengalami gangguan perkembangan halus di Indonesia. ${ }^{10}$ Proporsi perkembangan anak usia 36 - 59 bulan berdasarkan karakteristik usia anak yaitu : usia 36 - 47 sebesar $85,9 \%$, usia 48 - 59 sebesar $90,6 \% .{ }^{11}$ Terkait hal tersebut, perlu dilakukan upaya yang dapat meminimalisir jumlah gangguan perkembangan yang dialami anak balita sesuai kewenangan bidan. ${ }^{12}$

Salah satu kewenangan bidan sesuai Kepu tusan Menteri Kesehatan No. 900/MENKES /SK/VII/ 2002 tentang registrasi dan praktik bidan pada pasal 16 adalah melakukan pemantauan tumbuh kembang anak. Sangat penting melibatkan peran orang tua khususnya seorang ibu dalam melakukan deteksi dini tumbuh kembang anak karena pada umumnya seorang ibu lebih banyak bersosialisasi dengan anak di lingkungannya sehingga memudahkan dalam proses deteksi dini penyimpangan tum buh kembang anak. Salah satu upaya yang dapat dilakukan untuk meningkatkan pengetahuan serta kemampuan ibu dalam melakukan stimulasi tumbuh kembang anak adalah memberikan pelatihan SDIDTK khusus nya pada ibu yang memiliki anak usia $3-60$ bulan.

Berdasarkan hasil uji pre test dan post test pada tabel 1 di atas menunjukkan bahwa pencapaian skore responden mengalami peningkatan setelah diberikan pelatihan SDIDTK pada ibu yang memiliki anak usia 3 30 bulan begitu pula pada ibu yang memiliki anak usia 31 - 60 bulan. Pelatihan SDIDTK oleh bidan yang diberikan pada ibu balita sesuai dengan Peraturan Menteri Kesehatan No 66 Tahun 2014 tentang pemantauan pertumbuhan, perkembangan dan gangguan tumbuh kembang anak pasal 6 yang menge mukakan bahwa proses pemantauan partum buhan, perkembangan dan gangguan tumbuh kembang harus dilakukan secara kom prehensif dan berkualitas mulai dari kegiatan stimulasi yang memadai, deteksi dini dan intervensi dini gangguan tumbuh kembang anak melalui pencatatan kegiatan Deteksi Dini Tumbuh Kembang pada anak (DDTK), pemantauan tersebut dapat dilakukan oleh tenaga kesehatan, instansi terkait dan ma syarakat.

Faktor yang paling mempengaruhi status perkembangan balita adalah pendidikan orang tua (koef- $\beta$ 1,396, p-value 0,015, PR 4,039, CI 95\% 1,312-12,433. ${ }^{13}$ Peran kader berpengaruh terhadap pemberian stimulasi oleh ibu kepada anak, sehingga perlu pembinaan untuk kader tentang pemberian stimulasi perkembangan 
Available Online at http://journal.umgo.ac.id/index.php/madu

anak yang baik dan terarah melalui pelatihanpelatihan. ${ }^{14}$

Berdasarkan hasil analisis data penelitian ini dengan menggunakan uji T Paired Sample Test, diperoleh nilai $\mathrm{p}$ sebesar $0.000, \alpha=0.05$ $(\mathrm{p}<\alpha)$. Hal ini menunjukkan bahwa ada pengaruh pemberian pelatihan SDIDTK terhadap cara ibu melakukan stimulasi perkem bangan anak. Pelaksanaan pelatihan SDIDTK terhadap ibu balita ini sejalan dengan Peraturan Menteri Kesehatan No 66 Tahun 2014 tentang pemantauan pertumbuhan, perkembangan dan gangguan tumbuh kembang anak sehingga kemampuan ibu dalam melakukan pemantauan tumbuh kembang anak tersebut setelah diberikan pelatihan dapat memudahkan ibu dalam melakukan deteksi dini gangguan tumbuh kembang anak. ${ }^{15}$ Semakin dini diketahui terjadinya gangguan tubuh kembang anak maka secara dini anak tersebut men dapatkan penanganan yang berkualitas dari tenaga kesehatan sehingga dapat menghasilkan generasi penerus yang produktif dan berkua litas. Cara stimulasi oleh ibu dengan metode gambar lebih baik penga ruhnya terhadap perkembangan anak usia kurang dari tiga tahun dibandingkan dengan metode tulisan. ${ }^{16}$ Pelatihan deteksi dini tumbuh kembang anak lebih efektif pada kelompok ibu yang diberikan sesuai dengan usia tahapan tumbuh kembang anak. ${ }^{17}$ Orang tua yang memiliki pengeta huan dan keterampilan melakukan stimulasi perkembangan anak secara baik dan benar dengan menggunakan recycle toys sebagai Alat Permainan Edukasi (APE) dalam membantu stimulasi perkembangan anak. ${ }^{18}$ Pengetahun orang tua dalam melakukan stumiasi tumbuh kembang anaknya sangat penting dan bermanfaat dalam optimalisasi proses perkembangan anak, Ada manfaat pendi dikan kesehatan terhadap pengetahuan ibu tentang stimulasi perkembangan motorik kasar anak usia 1-3 tahun. ${ }^{19}$

\section{KESIMPULAN DAN SARAN}

Kesimpulan dalam penelitian ini adalah pelatihan Stimulasi Deteksi Intervensi Dini Tumbuh Kembang (SDIDTK) dapat memberi pengaruh terhadap cara ibu melakukan stimu lasi perkembangan anak usia 3-60 bulan di Kelurahan Karunrung Kota Makassar Tahun 2018. Terkait hal tersebut, terdapat beberapa saran dalam penelitian ini yaitu : institusi pendidikan, dapat melakukan kegiatan praktik mata kuliah komunitas yang tidak hanya kepada guru-guru TK tetapi dapat langsung memberikan pengetahuan dan pelatihan SDIDTK pada ibu-ibu yang memiliki anak usia 0-6 tahun.dan pihak pemerintah terkait dapat menambah personil tenaga kesehatan yang berkualitas untuk ditugaskan sebagai tenaga pelatih dan sosialisator mengenai tumbuh kem bang anak, khususnya SDIDTK.

\section{DAFTAR PUSTAKA}

1. Asiyah S, Harjito K, Suwoyo. 2010. Efektivitas metode stimulasi satu jam bersama ibu terhadap perkembangan anak usia 12-24 bulan. Jurnal Penelitian Kesehatan Suara Forikes. 2010 April; I: 105-14.

2. Yuliasti dkk. 2018. Modul Bahan ajar cetak keperawatan (online)http://bpps dmk.kemkes.go.id/pusdiksdmk/wpcontent/uploads/2017/08/Keperawata n-Anak-Komprehensif.pdf

3. UNICEF. 2011. ASI Eksklusif Tekan Angka Kematian Bayi Indonesia. (Online), http: //scholar.unand.ac.id/ 12557/2 /BAB\%20I\%20pdf.pdf. Diakses 09 Maret 2017.

4. Badan Pusat Statistik Jakarta Pusat. Statistik Indonesia Tahun 2010. Jakarta Pusat : Badan Pusat Statistik; 2010

5. IDAI. 2013. Mengenal keterlambatan perkembangan umum pada anak. (on line) http://www.idai.or.id/artikel/ 


\section{Made}

Jurnal Kesehatan
Vol 9, No 2 (2020), 14-20

ISSN 2301-5683 (print)

DOI: $10.31314 / \mathrm{mjk} \cdot 9.2 .14-20.2020$

Available Online at http://journal.umgo.ac.id/index.php/madu

seputar-kesehatan-anak/mengenal-

keterlambatan-perkembangan-umum-

pada-anak diakses tanggal 09 Maret 2017

6. Soetjiningsih, Ranuh. IG.N.G. 2014. Tumbuh Kembang Anak Edisi 2.EGC.Jakarta.(Online).http://scholar. unand. ac.id/12557/2/BAB\%20I\% 20 pdf.pdf. Diakses pada tanggal 09 Maret 2017, pukul 17:47 wita).

7. Malinda, dkk. 2013. Efek Stimulasi Terhadap Perkembangan Motorik Kasar Anak Usia 6-12 Bulan Di Kota Makassar Tahun 2013. Makassar. (Online), http://web cache.google user content. com/search?q=cache:GgRW 8YJT1xYJ:pasca.unhas.ac.id/jurnal/fil es/4d69a5527f1ccdd891dd11e172c19 944.pdf $+\& c d=3 \& \mathrm{hl}=\mathrm{id} \& \mathrm{ct}=\mathrm{clnk} \& \mathrm{gl}=$ id. Diakses 09 Maret 2017.

8. Fitriani, I. S., Oktobriariani, R. R. 2017. Stimulasi , deteksi dan intervensi dini orang tua terhadap pencegahan penyimpangan pertumbu han dan perkembangan anak balita. ISSN: 2549-2721 (Cetak), ISSN : 2549-2748 (Elektronik). Vol.1, No.1, Maret 2017: 01-09.

9. Soetjiningsih. 2012. Perkembangan Anak dan Permasalahannya dalam Buku Ajar I Ilmu Perkembangan Anak Dan Remaja. Jakarta: Sagungseto .Pp 86-90.

10. Kementerian Kesehatan RI, 2016. Pedoman pelaksanaan Stimulasi, Deteksi, Intervensi Dini Tumbuh Kembang. (online) https://banpaud pnf.kemdikbud.go.id/upload/ down load-

center/Buku\%20SDIDTK_155410745 6.pdf

11. Kementrian Kesehatan Republik Indonesia. 2013. Riset Kesehatan Dasar. Jakarta: Badan Penelitian Dan
Pengembangan Kesehatan Kemen terian Kesehatan RI.

12. Riskesdas. 2018. Hasil Utama

RISKESDAS (online) https://kesmas .kemkes.go.id diakses 10 Maret 2017

13. Makrufiyani, dkk. 2018. Faktor faktor yang mempengaruhi status perkembangan balita usia 1 - 3 Tahun di Wilayah Puskesmas Gamping II Sleman. (online) http://eprints .poltek kesjogja.ac.id

14. Khofiyah. 2020. Edukasi Berpengaruh terhadap Pemberian Stimulasi Perkemba ngan Anak Usia 12-24 Bulan oleh Ibu di Posyandu Desa Tambakrejo Kabupaten Puworejo (online) https://doi. org/10.266 99/jnk. v7i2.ART.p231-238

15. Permenkes RI. 2014. Peraturan Menteri Kesehatan Republik Indonesia Nomor 66 Tahun 2014 Tentang pemantauan Pertumbuhan, Perkembangan, dan Gangguan Tum buh Kembang Anak. (online) https:// dinkesjatimprov.go.id// userfile/ doku men/PMK\%20No.\% $2066 \% 20 \mathrm{ttg} \%$ 20Pemantauan\%20Tumbuh\%20Kemb ang\%20Anak.pdf di akses tgl 09 April 2017

16. Innike,dkk. 2014. Pengaruh pelatihan stimulasi keluarga oleh ibu dalam bentuk tulisan dengan gambar terhadap perkembangan anak usia kurang dari 3 tahun. Sari pediatri Vol $\begin{array}{llll}16, \quad \text { No } & 4 & (2014) & \text { (online) }\end{array}$ https://saripediatri. org/index. php/saripediatri/article/view/216

17. Muflihah. 2015. Efektifitas pelatihan deteksi dini tumbuh kembang sesuai tahapan usia anak terhadap penge tahuan dan keterampilan ibu dalam men stimulasi tumbuh kembang balita. MEDISAINS: Jurnal Ilmiah Ilmu-ilmu Kesehatan, Vol 13 No 1, APRIL2015 
Available Online at http://journal.umgo.ac.id/index.php/madu

(online) jurnal nasional. ump.ac.id/ index. $\mathrm{php} /$ medisains /article /down load/1822/1499

18. Tentama,dkk. 2017. Pelatihan Tum buh Kembang Anak Untuk Mening katkan Ketrampilan Stimulasi Orang Tua Anak Usia Dini. Buletin Udayana Mengabdi. Volume 16 Nomor 3, September 2017 (online) http:// ojs. unud .ac.id

19. Dewi. 2019 Manfaat pendidikan kesehatan terhadap pengetahuan ibu tentang stimulasi perkembangan motorik kasar anak usia 1-3 tahun. (online) http://repo sitory .itspku.ac.id 